\title{
Coral reef science and the new commons
}

\author{
R. H. Bradbury $\cdot$ R. M. Seymour
}

Received: 12 April 2009/Accepted: 4 August 2009/Published online: 23 August 2009

(C) Springer-Verlag 2009

Keywords Global change - Globalisation ·

Anthropocene $\cdot$ Ecosystem collapse

We humans have inadvertently triggered the emergence of a new Earth system: a new geological epoch called the Anthropocene (Crutzen 2002; Steffen et al. 2007). It is replacing the Holocene, the epoch in which civilisation evolved. Coral reefs, together with all other ecosystems on the planet, are being swept up in this change.

The changes are so complex that they are overwhelming the ability of traditional science to comprehend them, and their consequences are so profound that they demand a new compact between science and society. This compact, we shall argue, is really an old one, but one, nevertheless, that is new to coral reef science. Coral reef science is doomed to irrelevance unless it embraces it.

In this view, the issue is not to 'save' coral reef ecosystems from humans but to reshape them to survive the Anthropocene together with humans-it is not to conserve species as an end in itself but to retain useful system functions and hence fitness for their joint purpose with humans.

Communicated by Editor-in-Chief Professor Rolf PM Bak.

R. H. Bradbury $(\bowtie)$

Resource Management in Asia-Pacific Program, College of Asia and the Pacific, Australian National University, Canberra, ACT 0200, Australia

e-mail: roger.bradbury@anu.edu.au

URL: http://rspas.anu.edu.au/blogs/rmap/

R. M. Seymour

CoMPLEX, University College London, Gower Street,

London WC1E 6BT, UK

e-mail: r.seymour@ucl.ac.uk

URL: http://www.ucl.ac.uk/CoMPLEX/
This is not to rail against science itself. Coral reefs, like many ecosystems, face an existential crisis, and science is vital to its resolution. But, if there is to be a resolution, it will not be in the way that many reef scientists currently believe. Rather, the solution will be through new science built on an old compact with society. This optimistic compact describes the 'how and why' of the application of science to the human condition-engineering in its best and broadest sense.

Indeed, we shall argue that the compact needs to drive the creation of a new commons for coral reefs-a closely managed commons that replaces today's tragedy (Hardin 1968) and actively reshapes coral reefs for the Anthropocene. We suggest that such a commons will restore our science to a healthier place in society. Today, coral reef science may seem to be part of a coral reef industry that sometimes has more to do with ideology than science, and that often places people in opposition to coral reefs. A more relevant coral reef science could foster an optimistic but realistic - an almost Victorian-awareness that coral reefs can be shaped successfully for our beneficial use.

\section{Globalisation is transmuting all ecosystems ...}

The Anthropocene is shaped by the existence of man. In just a few tens of thousands years, this species has changed the world's fundamental biogeochemical cycles and climate (Gruber and Galloway 2008). Man has also profoundly shifted the global distribution of biomass and biodiversity. We don't yet know the details of the Anthropocene, nor how it will play out over the long haul. Its future as a complex system is both undetermined and unpredictable (Bradbury 2006), but we can now see its shape emerging clearly.

The great ecologist, Hutchinson (1965), saw the world as an evolutionary play in an ecological theatre. Man has 
trashed the theatre, a new one is rising, and a new play has begun. The curtain has come down on the pristine world and the play called the Garden of Eden. In its stead, there is a new play called globalisation. The star of the show is human population growth, with strong supporting roles for economic growth, global warming, overfishing, deforestation, dam building, agriculture, fertiliser use and many more (Steffen et al. 2007).

These actors interact in complex ways and at different scales. For example, increasing gross domestic product (GDP), through increasing energy use is reflected as increasing temperatures at the global scale, and through increasing agricultural production as increasing coastal runoff of polluted rivers at the local scale. Increasing human population is reflected as increased tourism pressure on coral reefs at the local scale, and as the collapse of reef fisheries at the regional scale.

The forces unleashed by globalisation are vast, are accelerating and have great inertia. They are-in the short to medium term-unstoppable and irreversible. They are smashing up and reshaping all ecosystems on Earth, including coral reefs, slowly suffocating regional and local mitigation efforts. The ups and downs of financial cyclesincluding, indeed, the current Global Financial Crisis-are mere blips on this centuries old trend (Pandolfi et al. 2003).

Wilderness-by which we mean ecosystems unlinked through man-has all but ceased to exist. The last remnants - in the high seas-are being brought into the new global system now. The land, where people live, is becoming a new single, tightly interconnected, and greatly simplified agro-ecosystem (Steffen et al. 2007) whose contradictions in terms of energy and mass fluxes and balances will be resolved in the sea, where people don't live. The sea is on a trajectory to becoming a vastly simplified super-ecosystem whose closest historical analogue will be the pre-Cambrian seas dominated by life forms such as jelly animals and algae (Jackson et al. 2001; Pandolfi et al. 2005). Coral reefs must find their future within this world if they are not fated to be just road-kill on the highway to the emerging Anthropocene, collateral damage as the new Earth system takes shape.

\section{... especially coral reefs}

The forces shaping the Anthropocene have two critical features. First, they are accelerating — global GDP is a good simple proxy which shows a compounding growth rate of ca $5 \%$ p.a. (Steffen et al. 2007; World Bank 2008) and so an exponential doubling time of about 15 years. Second, they have inertia-because of the time scales intrinsic to both natural and human systems, there is no real prospect of changing their trajectories in less than $20-50$ years. For coral reefs in particular, two forces stand out-overfishing and $\mathrm{CO}_{2}$ emissions. Were each to act alone, they could cause the collapse of the world's coral reefs by 2050 . Together they have a good chance of doing it by 2025 .

Consider $\mathrm{CO}_{2}$ emissions-the main driver of global warming and ocean acidification. They are now above the most pessimistic IPCC projections (Raupach et al. 2007) as the world economy becomes more not less carbon intensive (Canadell et al. 2007), and they are accelerating. We also know that $\mathrm{CO}_{2}$ emissions have terrific inertia-there is at least $0.6^{\circ} \mathrm{C}$ already 'in the pipeline' (Hansen et al. 2005); emitting infrastructure has a $>20-50$ year half life (International Energy Agency 2008), and complex international agreements (such as would be needed to change this infrastructure) have rarely been made in $<20-50$ years. This means that there is a high probability of $>2^{\circ} \mathrm{C}$ increase in global temperatures by 2050 and a reasonable probability of $>2^{\circ} \mathrm{C}$ by 2025 . As a result-regardless of any feasible international action over the next 20 years-coral reefs are almost certain to cross the temperature/pH threshold for survival by 2050 and are likely to cross it by 2025 (Hoegh-Guldberg et al. 2007).

Now consider overfishing. We know that global fishing pressure is accelerating, probably ahead of global GDP (Berkes et al. 2006; Scales et al. 2006; Worm et al. 2006; Halpern et al. 2008; Jackson 2008). We also know that global fish catch is declining (Pauly 2008). The terrible math of exponential growth means that since the ICRS symposium in Panama in 1996, when Jeremy Jackson talked about the existential threat to coral reefs posed by overfishing (Jackson 1997), fishing pressure on coral reefs has essentially doubled. As with $\mathrm{CO}_{2}$ emissions, we also know that overfishing has stunning inertia-coral reefs have not yet equilibrated to the great removal of large fish in the 1960s and 1970s (Hughes 1994; Myers and Worm 2003; Worm et al. 2005; Sibert et al. 2006; Myers et al. 2007); and the global fishing industry is overcapitalised and subsidised by governments - a huge structural adjustment issue which has successfully resisted change for the last 40 years and is unlikely to change in the next 20 years (Pauly et al. 2002). This means that on these locked-in trends, overfishing, by itself, will almost certainly cause the collapse of $>95 \%$ of the world's coral reefs by mid-century, and is likely to do so by 2025 .

\section{But coral reef science has lost the plot ...}

Coral reef science has lost its way on the coral reef crisis because it has lost its perspective on what the problem is. It imagines the problem to be something to do with the protection of reefs from outside influences-from 'the other'-and the solutions it offers mostly have to do with 
creating barriers-usually legal, sometimes physical-to stop those influences seeping into reef ecosystems. Any nineteenth-century conservationist would recognise the strategy (Leopold 1949) and most twentieth-century 'environmentalists' would reflexively endorse it.

But the contingency of the Anthropocene swamps all barriers and creates a new Earth system within which coral reef ecosystems must find their place. Coral reef science, inward-looking, cannot see this because it has cut itself off from developments elsewhere in science that encourage thinking about systems within systems. It has not learned the key lesson of the Anthropocene: that there is no 'other' that coral reefs are separate from.

The coral reef crisis in the Anthopocene is not caused by humans crossing some boundary and intruding into coral reefs, nor does any solution have much to do with managing that boundary. Coral reefs and humans are both components of the larger Earth system and it makes no sense to idealise coral reefs as some sort of human-free zone. Coral reefs are so intimately interconnected with humans that it is no longer possible, if it ever was, to consider them apart.

The complex systems revolution of the last 20 or 30 years (Levins 1970; Holland 1998; Wolfram 2002) has given science access to such thinking as well as to a toolbox and a penchant for multidisciplinary work. But it seems to have left coral reef science largely untouched, even as it has made profound changes to the way in which much science on the high frontier is now done. It is now deeply embedded, for example in molecular biology where, under the rubric 'systems biology', it has become the 'big idea'.

\section{... while systems biology got it right}

Systems biology is the rapidly growing movement that has arisen in reaction to a half-century of reductionist research that began with the molecular biology revolution in the 1950s. Whilst not denying the great gains that have been, and are still being made through this reductionist approach, systems biology aims to reverse the paradigm in which more-and-more-detailed properties of smaller-and-smaller components of biological systems are isolated and dissected. Systems biology brings together scientists from many disciplines-not only traditional lab-based biologists, but also physicists, engineers, mathematicians and computer scientists - to pursue a reverse, integrationist agenda with the aim of understanding how whole system properties 'emerge' from component processes. It is these emergent properties that promise significant payoffs to humans, especially in the field of medical applications.

The systems biology movement for the most part has centred at the biology of the cell but is vigorously extending its reach upwards to the level of organs. But so far, ecology has been largely unaffected by this scientific revolution, remaining stuck with its classical 1960s 'systems analysis' paradigm. Ecosystems are conceived as assemblages that just 'do what they do', and ecologistsand reef scientists in particular-try to understand this 'doing' through a detailed description of system components and their (mostly) local-scale interactions: recruitment, growth, competition, predation, trophic cascades, energy fluxes and the like.

But a systems biology approach turns this view of coral reef ecosystems on its head, and, as we argue below, offers the opportunity to paint a new future for coral reefs on the larger canvas of the Anthropocene. Such an approach points to a view of coral reefs as taking a dynamic part in the creation of the emerging Earth system of the Anthropocene by interacting with all other parts of that system including the human socio-economic system.

Much lip service (and some limited action) is paid to integrating socio-economic components into coral reef conservation science: for example, by consulting local stakeholders to obtain compliance with MPAs. However, within this now widely accepted paradigm, the tendency is for the domains covered by the ecologists (the reef ecosystem) and by the sociologists and development economists (the characteristics of the coastal population) to be acknowledged as 'boundary conditions' for each other's activity. The ecologist asks: what is the nature of the interaction of coastal populations with the reef system, and how can we minimise its impact with the aim of preserving biodiversity and ecosystem function (conceived in ecological terms). The social scientist asks: what are the implications for social behaviour of the dependency of human populations on natural systems, and how can this be used to promote human development (conceived in terms of wealth and/or asset generation).

Neither side seriously asks what are the emergent properties of the integrated system, and how do these characterise whole-system behaviour. Nor do they ask how such an integrated system might function and how we might promote its 'health'. Such ideas are outside the worldview of today's coral reef science as are strategies that help fit coral reef ecosystems into the emerging Earth system of the Anthropocene.

\section{And purpose comes for free}

To understand what it means for an integrated system to be 'healthy', it helps to think in physiological terms. Physiological systems are largely regulated by homeostatic control structures. Hearts and lungs have a more or less clear function, they are 'for' some purpose. Generally speaking, 
control structures try to maintain the system function within a neighbourhood of its purpose. So system health can be characterised by how well the control structures match system function with purpose.

This idea of system health thus begs the question of what ecosystems might be 'for', because health, at a minimum, must have to do with being in a neighbourhood of some desirable system state. Ecosystems as conceived by most ecologists, because they just 'do what they do', cannot be understood in these terms. Instead they merely exist (Bradbury and Antonelli 1985). But because ecosystems integrated with human systems can have homeostatic control structures (even if they are only weakly effective), they can be purposeful, and so they can have health.

But the 'healthy' neighbourhood of this high-level purpose may well be large, so that there may not be only one relevant notion of 'health'. Rather, there may be a whole spectrum of states that are regarded as healthy in some dimension of evaluation-states in which the system functions effectively within a relevant setting. Crucially, for integrated human/coral reef systems, such states need not automatically give primacy to the traditional measures valued by conservationists, such as maintaining biodiversity and preservation of 'pristine' natural systems. Neither do they necessarily give primacy to traditional indicators of human welfare such as economic growth and per-capita GDP (Sen 1999).

Thus, in the absence of naturally evolved ecosystem functions (that is, purposes), we may find functions in the integrated human-ecosystem whole. We may then use these identified functions as high-level organising principles for understanding how to intervene, that is, for developing homeostatic controls. Thus, they may provide a scientific basis for policy development and hence a new and enduring relevance for coral reef science.

Such 'functions' must be defined in terms that include the parameters of human activity, and the resulting management responses should aim to buffer associated homeostatic properties that maintain these functions. In this endeavour we should think more like agricultural scientists, using a wider range of tools than is common in natural system management, such as manipulative techniques like optimisation by selective breeding or by introducing alien species (Briggs 2008; Hoegh-Guldberg et al. 2008).

\section{Purpose grounds a new science for coral reefs}

In developing views of what it means for integrated humanreef systems to be healthy, we must escape from the prevailing idea that reef management is largely concerned with preserving 'wilderness'. We have already made an analogy between human-ecosystems and physiological systems, with their associated homeostatic characteristics. Closer to home, we can make an analogy between ecosystems and agricultural systems-systems that are 'natural' in the sense of being based on (mostly) organic constituents and processes, but which are at the same time highly integrated with, and managed by, humans. Maintaining wilderness is not the only option in agricultural systems, but part of a much wider spectrum of 'exploitation'. Agricultural systems, like physiological systems, have functions, whose 'health' is defined by how well they fulfil their roles within the integrated human-natural interactive landscape.

Agricultural systems are exploitative in the obvious sense that humans design, build and make use of them for their own purposes. However, they are vital to human welfare, and their healthy functioning is a matter of great concern to humanity. We need to get away from the idea that conservation is good and exploitation is bad. In reality there is a whole spectrum of levels of exploitation of natural systems that humans have developed. Preservation (or restoration) of 'wilderness' is not the only-or the most important—stance we can take vis-à-vis the natural world.

Humans have been exploiting and changing landscapes on a significant scale ever since the Neolithic, but especially since the agricultural revolution, which began at the end of the last ice age about 10,000 years ago, and subsequently accelerated with the industrial revolution beginning in the early eightieth century. In the course of this history, humans have developed a whole spectrum of levels of exploitation, control and management of natural systems, including:

- Set aside wilderness (e.g., national parks)—with very low exploitation

- Semi-conserved and un-restructured landscapes (e.g., mudflats) - with low levels of exploitation, such as shellfish collection

- Semi-conserved and restructured (e.g., much moorland habitat whose natural state would be scrubland or low canopy forest) - with low to medium levels of exploitation such as sheep grazing, some low-intensity farming or recreational hunting

- Restructured and actively managed (e.g., much temperate farmland)—with medium to high levels of exploitation

- Highly restructured and highly actively managed (e.g., high intensity farming, as in the American prairies) with very high levels of exploitation in what are basically outdoor factories.

The problems we face in the management of these systems are largely those of success, the most conspicuous symptom of which is the massive and accelerating growth in the human population over the last few centuries.

Human needs cannot be neglected, in spite of the obvious and well-rehearsed problems we face in our 
relations with the natural world. Certainly, mistakes have been made along the way-causing great ecological damage-mostly through ignorance. Large dams, overgrazing, salination, desertification, deforestation, overfishing, eutrophication create a depressing refrain echoed again and again around the world (Diamond 2005).

However, we have no option but to press on, learn from our mistakes as best we can, and continue managing the landscape-which, in the Anthropocene, is all the worldand facing all the tradeoffs that this entails. These tradeoffs are inherent in any 'political economy' and certainly in the integrated human-ecosystems with which we are concerned. The interests of all stakeholders must be acknowledged. But what must also be acknowledged is that we humans are the only players who can hope to organise and manage these systems with any strategic vision.

\section{A new science for the new commons}

There is clearly a richer palette of ways humans interact with ecosystems on the land than in the sea. As terrestrial animals, humans put more of their energy and ingenuity into terrestrial systems. But we should not imagine that we cannot do the same in the sea. In particular, with coral reef systems, which interact with humans very directly due to their proximity to coastal populations. How are we to achieve this? We think it will require a new kind of integrated science-not just a new kind of coral reef science.

The urgent need is for focus and action on scales that are commensurate with the problems we face. The current vision is one of conservation by protection-managing the activities of coastal populations with the aim of minimising their impact on reefs. Rather than conservation, this is just a form of genteel managed decline. To escape from this decline, coral reef science needs a transformative moment.

We have to learn the skills to enable us to interact constructively with coral reefs for the benefit of the whole Earth system. This will require a new science of managed marine landscapes. There will always be a need for basic science, but this is no longer enough. Creating a systems biology paradigm in ecosystem science will require multidisciplinary input, with scientific interactions not just at the margins of each discipline, but focused collaboratively on the realisation of a vision of healthy functioning of humanreef systems. This will require new kinds of scientists (with new kinds of career structures) who are trained to work in multi-disciplinary teams. The need for such training is now widely recognised in the laboratory-based life sciences, and initiatives to provide it are in train (Biotechnology and Biological Sciences Research Council 2005; National Science Foundation 2009). Such initiatives are urgently needed in the human-ecosystems interaction domain, but are as yet barely visible.

A bigger, more proactive vision of controlled development must be created, which promotes the active reinforcement of homeostatic structures-that is, processes that maintain a strategic conception of 'healthy' human-ecosystem functioning. We need to create the reefscapes we want. And so, we need to discover what to do, at what scale, in what modality-ecosystem engineering, farming, legislation, social organisation, economic initiatives, etc.- -and how to do it. Since the system is integrated, action must also be integrated over all these modalities.

What are the relevant components of the system? We already know quite a lot about the main players, even if we don't know everything we would like to about how they interact in detail. There are components of benthic habitats, fish and invertebrate stocks at various trophic levels, associated coastal habitats such as mangrove forests and sea-grass beds, as well as socio-economic components such as fishing pressure, tourism pressure, coastal agricultural activity and urban development, all increasing with increasing population pressure. To actively manage, intervene and restructure these complex systems-using these components as functional building blocks, rather than obsessing about particular species-will require the development of new engineering, husbandry and political skills.

To actively reinforce homeostatic properties, we should aim to keep relevant measures within agreed bounds, e.g., stock levels for economically important fish species. So, economically important fish stocks that are depleted by fishing should be replenished from nurseries. The fishery can be managed by understanding the life history of the fish, and designing suitable nurseries exactly for this purpose. This would then be a species of 'farming' the commons. But, there may be tradeoffs involved in doing this, such as loss of some aspects of benthic structure and biodiversity.

Similarly, if we want coral reefs to help buffer coastal erosion, there is really no reason why the natural system should not be artificially reinforced to do this. But, this could have knock-on effects that in other circumstances would be considered undesirable-perhaps by blocking off turtle breeding sites.

Choices must be made, and tradeoffs faced. We should therefore not be shy about declaring what relevant ecosystems are 'for' - that is, what functions they should serve in the context of human-ecosystem interaction. This will inevitably be a deeply political question, so that coral reef management necessarily is a political process taking place in a definite socio-economic context. Once such functions are agreed, instances of ecosystems should be managed with a view to optimising these, even if this leads to consequences 
such as loss of biodiversity (as in most agricultural systems), though we may well decide that maintaining a reservoir of biodiversity is the relevant function in some instances (e.g., as in terrestrial national parks and MPAs), perhaps with a view to promoting education and the more benign varieties of tourism.

\section{Living in the real world}

This is our rugged new world. There is hard, new work to be done. Both the land and the sea will be inherently unstable and so need to be tightly managed. We will need to manage coral reef ecosystems through the transition to the Anthropocene that is now upon us and into a restructured future shape, preserving what we can of their ecosystem function, possibly at the expense of their current biodiversity and structure (Bradbury 2000; Hennessey and Sutinen 2005). But current policy settings and resource management strategies are focussed on preserving reefs in something like their present Holocene state. Coral reef science, instead of leading policy and management to recognise the reality of the Anthropocene, follows them to some Edenic fantasy.

Emergency measures will be needed-perhaps for a century or more-whilst we attempt to stabilise the Earth's major regulatory systems, and coral reefs need to be a focus for some of these measures. We may need to restore sufficient function to some coral reefs to allow their richer interaction with human systems, say for fisheries, aquaculture or coastal protection. But that restoration will need to be at a scale and of a quality that will challenge both our science and our beliefs. We foresee the need for bio- and geo-engineering at the scale of whole reefs, the translocation of functional groups of fish or corals between oceans and hemispheres, and the deliberate transformation of damaged reefs into pseudo-reefs that capture only some reef functions, but are nonetheless useful parts of the integrated human-reef system.

The situation is so serious that risks will need to be taken on the basis of uncertain knowledge. Doubtless, mistakes will be made. But coral reef science can no longer hide down in the weeds. As Jackson (1997) said:

coral reef ecologists have been so devoted to dissecting small scale processes that they have not seen the reefs for the corals.

Indeed coral reef scientists need to get out more. Instead of issuing earnest declarations to 'save' coral reefs at every international meeting, they need to accept that there is no such thing as a natural ecosystem anymore. They need to realise that whatever ecosystems 'do' is now deeply intertwined with human activity. We should therefore manage human-ecosystems interactions with this in mind-that is, with human purposes in mind, just as we do agricultural systems, in their many varieties.

We need to learn the skills to scale up our thinking to whole systems, and then to intervene to regulate these systems. This is the traditional domain of engineers, who are informed by science, but not constrained by it. A new science built on an old compact with society-the practice of engineering as 'social science'-is needed. To effect the appropriate changes will require political vision and political will-and money.

Our takeaway message is that hard choices cannot be avoided, and a larger conception of 'management' should be developed and undertaken with this firmly in mind. There is no 'natural' commons any more. Tradeoffs have to be faced, a process that will be continually evolving with human needs. We must forget the naive 'green' idea that ecosystems are 'out there' and would just get on with 'doing what they do' in a 'harmonious' way, if only we humans would leave them alone.

There is no way back to the Garden of Eden.

Acknowledgments We presented two papers-one on the problem, one on the solution—at the 11th ICRS in Fort Lauderdale in July 2008. This paper distils their liquor. It is a contribution from the World Bank Coral Reef Targeted Research Program (www.gefcoral.org). We thank our colleagues in the CRTR's Modelling \& Decision Support Working Group for their robust comments and criticism as we developed these ideas.

\section{References}

Berkes F, Hughes TP, Steneck RS, Wilson JA, Bellwood DR, Crona B, Folke C, Gunderson LH, Leslie HM, Norberg J, Nystrom M, Olsson P, Osterblom H, Scheffer M, Worm B (2006) Globalization, roving bandits, and marine resources. Science 311:15571558

Biological Biotechnology Sciences Research Council (2005) World class bioscience: Strategic plan 2003-2008. Biotechnology and Biological Sciences Research Council, London

Bradbury RH (2000) Will the new science of complexity subvert oceans policy? In: Wilson D, Sherwood R (eds) Oceans governance and maritime strategy. Allen and Unwin, Sydney, pp 191-198

Bradbury RH (2006) Towards a new ontology of complexity science. In: Perez P, Batten D (eds) Complex science for a complex world: Exploring human ecosystems with agents. Australian National University E Press, Canberra, pp 21-26

Bradbury RH, Antonelli PL (1985) On the existence, or not, of coral reefs. 5th Int Coral Reef Congr 6:329-333

Briggs JC (2008) Atlantic coral reefs: the transplantation alternative. Biol Invasions. doi: 10.1007/s10530-008-9363-6

Canadell JG, Le Quere C, Raupach MR, Field CB, Buitenhuis ET, Ciais P, Conway TJ, Gillett NP, Houghton RA, Marland G (2007) Contributions to accelerating atmospheric $\mathrm{CO} 2$ growth from economic activity, carbon intensity, and efficiency of natural sinks. Proc Natl Acad Sci USA 104:18866-18870

Crutzen PJ (2002) Geology of mankind. Nature 415:23-23

Diamond J (2005) Collapse: How societies choose to fail or survive. Allen Lane, London 
Gruber N, Galloway JN (2008) An Earth-system perspective of the global nitrogen cycle. Nature 451:293-296

Halpern BS, Walbridge S, Selkoe KA, Kappel CV, Micheli F, D'Agrosa C, Bruno JF, Casey KS, Ebert C, Fox HE, Fujita R, Heinemann D, Lenihan HS, Madin EMP, Perry MT, Selig ER, Spalding M, Steneck R, Watson R (2008) A global map of human impact on marine ecosystems. Science 319:948-952

Hansen J, Nazarenko L, Ruedy R, Sato M, Willis J, Genio AD, Koch D, Lacis A, Lo K, Menon S, Novakov T, Perlwitz J, Russell G, Schmidt GA, Tausnev N (2005) Earth's energy imbalance: Confirmation and implications. Science 308:1431-1435

Hardin G (1968) The tragedy of the commons. Science 162:1243-1248

Hennessey T, Sutinen JG (eds) (2005) Sustaining large marine ecosystems: The human dimension. Elsevier

Hoegh-Guldberg O, Mumby PJ, Hooten AJ, Steneck RS, Greenfield P, Gomez E, Harvell CD, Sale PF, Edwards AJ, Caldeira K, Knowlton N, Eakin CM, Iglesias-Prieto R, Muthiga N, Bradbury RH, Dubi A, Hatziolos ME (2007) Coral reefs under rapid climate change and ocean acidification. Science 318:1737-1742

Hoegh-Guldberg O, Hughes L, McIntyre S, Lindenmayer DB, Parmesan C, Possingham HP, Thomas CD (2008) Assisted colonization and rapid climate change. Science 321:345-346

Holland JH (1998) Emergence: From chaos to order. Oxford University Press, Oxford

Hughes TP (1994) Catastrophes, phase shifts, and large-scale degradation of a Caribbean coral reef. Science 265:1547-1551

Hutchinson GE (1965) The ecological theatre and the evolutionary play. Yale University Press, New Haven

International Energy Agency (2008) World Energy Outlook 2008. International Energy Agency, Paris

Jackson JBC (1997) Reefs since Columbus. Coral Reefs 16:S23-S32

Jackson JBC (2008) Ecological extinction and evolution in the brave new ocean. Proc Natl Acad Sci USA 105:11458-11465

Jackson JBC, Kirby MX, Berger WH, Bjorndal KA, Botsford LW, Bourque BJ, Bradbury RH, Cooke R, Estes JA, Hughes TP, Kidwell S, Lange CB, Lenihan HS, Pandolfi JM, Peterson CH, Steneck RS, Tegner MJ, Warner RR (2001) Historical overfishing and the recent collapse of coastal ecosystems. Science 293: 629-638

Leopold AS (1949) Sand county almanac. Oxford University Press, New York

Levins R (1970) Complex systems. In: Waddington CH (ed) Towards a theoretical biology 3 Drafts. Edinburgh University Press, Edinburgh, pp 73-88

Myers RA, Worm B (2003) Rapid worldwide depletion of predatory fish communities. Nature 423:280-283

Myers RA, Baum JK, Shepherd TD, Powers SP, Peterson CH (2007) Cascading effects of the loss of apex predatory sharks from a coastal ocean. Science 315:1846-1850
National Science Foundation (2009) Interdisciplinary training for undergraduates in biological and mathematical sciences. National Science Foundation, Washington, DC

Pandolfi JM, Bradbury RH, Sala E, Hughes TP, Bjorndal KA, Cooke RG, McArdle D, McClenachan L, Newman MJH, Paredes G, Warner RR, Jackson JBC (2003) Global trajectories of the longterm decline of coral reef ecosystems. Science 301:955-958

Pandolfi JM, Jackson JBC, Baron N, Bradbury RH, Guzman HM, Hughes TP, Kappel CV, Micheli F, Ogden JC, Possingham HP, Sala E (2005) Are U.S. coral reefs on the slippery slope to slime? Science 307:1725-1726

Pauly D (2008) Coral reef fisheries - a re-assessment of their ecological and socioeconomic impacts 11th Int Coral Reef Symp: 'in press'

Pauly D, Christensen V, Guénette S, Pitcher TJ, Sumaila UR, Walters CJ, Watson R, Zeller D (2002) Towards sustainability in world fisheries. Nature 418:689-695

Raupach MR, Marland G, Ciais P, Le Quere C, Canadell JG, Klepper G, Field CB (2007) Global and regional drivers of accelerating CO2 emissions. Proc Natl Acad Sci USA 104:10288-10293

Scales H, Balmford A, Liu M, Sadovy Y, Manica Andrea, Hughes TP, Berkes F, Steneck RS, Wilson JA, Bellwood DR, Crona B, Folke C, Gunderson LH, Leslie HM, Norberg J, Nystrom M, Olsson P, Osterblom H, Scheffer M, Worm B (2006) Keeping bandits at bay? Science 313:612-614

Sen A (1999) Development as freedom. Oxford University Press, Oxford

Sibert J, Hampton J, Kleiber P, Maunder M (2006) Biomass, size, and trophic status of top predators in the Pacific Ocean. Science 314:1773-1776

Steffen W, Crutzen PJ, McNeill JR (2007) The Anthropocene: Are humans now overwhelming the great forces of nature? Ambio $36: 614-621$

Wolfram S (2002) A new kind of science. Wolfram Media, Champaign, IL

World Bank (2008) World Development Indicators 2008. World Bank, Washington, DC

Worm B, Sandow M, Oschlies A, Lotze HK, Myers RA (2005) Global patterns of predator diversity in the open oceans. Science 309:1365-1369

Worm B, Barbier EB, Beaumont N, Duffy JE, Folke C, Halpern BS, Jackson JBC, Lotze HK, Micheli F, Palumbi SR, Sala E, Selkoe KA, Stachowicz JJ, Watson R (2006) Impacts of biodiversity loss on ocean ecosystem services. Science 314:787-790 